\title{
CULTIVATING VOLUNTARY ONLINE LEARNING COMMUNITIES IN BLENDED ENVIRONMENTS
}

\author{
Robert Heckman \\ Syracuse University \\ Hala Annabi \\ University of Washington
}

\begin{abstract}
In this paper we argue for the possibility of using asynchronous technology to create a continuous, voluntary learning community in face-to-face courses. We discuss the theoretical concepts and values that are the foundation of such a community, describe some of the activities that take place there, and present principles of cultivation that we believe will help instructors nurture such communities in their own classes. The examples we present suggest that the emergence of a voluntary online learning community is possible in any course. Nevertheless, more research is necessary to better understand the nature of such learning communities, and we present a research agenda for the future study of this phenomenon.
\end{abstract}

\section{KEYWORDS}

Learning Community, Face to Face, Voluntary, Blending, Community of Practice, Democratic, Trust

\section{INTRODUCTION}

As teachers and institutions have become more sophisticated in integrating information and communication technology (ICT) into educational environments, they have begun to recognize that blended or hybrid learning is an approach that has great potential to improve learning outcomes. While "blended learning" can mean many different things to different people [1], we focus here primarily on the use of asynchronous technology to enhance traditional face-to-face (FTF) classes in graduate and undergraduate higher education. Teachers in traditional classrooms have begun to recognize that some of the most basic and familiar forms of online technology (e.g. asynchronous bulletin boards, listserves, chat rooms, etc.) have the power to add significant benefit to the traditional FTF, lecture based instructional mode. In some versions of blended learning, online activities replace a portion of the FTF "contact hours.” In others, online activities supplement rather than replace classroom work.

Blended learning methods have the potential to combine the benefits of both FTF and online learning. Benefits of asynchronous online learning include increased reflection time, more democratic participation, and higher level cognitive activity [2-4]. Benefits of FTF courses include high level of social presence, immediate feedback, ease in communication and information sharing [5]. When able to choose educational activities from both online and FTF mediums, instructors can potentially select the activity that provides the best fit with any particular learning objective. Because of this ability to combine the benefits of both modes, some researchers have argued that blended learning has the potential not only to enhance the effectiveness and efficiency of learning experiences, but also to fundamentally transform the nature of post secondary education [6]. 
But despite this potential, many students, faculty, and administrators believe that instructional technology has had little impact on learning. A recent survey of 4374 undergraduates at 13 colleges, conducted by the Educause Center for Applied Research [7], suggests that students perceived relatively little benefit from instructional technology in the classroom. According to the survey, $48.5 \%$ of the students recognized the convenience benefits of information technology, but only $12.7 \%$ of the students felt that improved learning was the greatest benefit of the new technology. It is clear that simply making technology available is not sufficient to create educational benefit. Professors must develop the skills and techniques necessary to use instructional technology effectively, and we are relatively early in the adoption cycle.

Thus, when it comes to using instructional technology in conjunction with traditional, FTF classroom activities, several fundamental questions remain:

- How can teachers best employ online technologies to support instructional objectives in the FTF classroom?

- What is the optimal blend of FTF and online activities?

- What teacher behaviors enhance the learning experience and learning outcomes in the blended mode?

In this paper we explore these questions by using, as a conceptual lens, the concept of a voluntary online learning community. In a voluntary online learning community, information and communication technologies give us the power to transform the traditional once or twice per week classroom meeting into an educational and social resource that is available to its members (students, teachers, and visitors alike) on a continuous, 24-hour, seven day per week basis. While there have been examples of learning communities emerging spontaneously in traditional, FTF classes (e.g. students sometimes form study groups), they generally involve small groups of students, not the whole class. The more typical case is that students and instructors have little or no contact with one another except during the weekly threehour meeting.

We ground our investigation of continuous learning communities by drawing on work in two closely related areas. First, we review literature on communities of inquiry [8, 9]. We employed the community of inquiry model because the online learning community we envision is a specific manifestation of the broader community of inquiry concept. By examining the principles that have been developed to create effectively functioning communities of inquiry, we hope to learn how to more effectively leverage asynchronous technologies to augment the FTF classroom.

In addition, we examine the literature on an organizational learning phenomenon that has been increasingly studied in recent years: communities of practice. The community of practice is becoming a widely recognized organizational learning structure in corporate life. The community of practice is a tool that permits those who voluntarily choose to participate to come together and share knowledge and expertise. An examination of the community of practice literature suggests that there are many commonalities between a community of inquiry and a community of practice. By exploring the similarities and differences between these two types of collaborative learning structures, we hope to uncover principles that might be useful in developing a continuous, voluntary online learning community in a blended learning environment.

After a brief review of literature on communities of inquiry and communities of practice, we will give several examples of a continuous learning community in action. We will then present principles to help teachers cultivate continuous learning communities in their own blended courses. Finally, we will discuss a research agenda that will allow us to more systematically explore continuous online learning 
communities in blended environments.

\section{BACKGROUND}

\section{A. Community of Inquiry}

A community of inquiry is a group of people who share a common educational objective, and who pursue this objective by interacting on an ongoing basis. Garrison et al. [8] suggest that for a community of inquiry to emerge, interaction of cognitive presence, social presence and teaching presence is necessary. The notion of a "community of inquiry" probably has its antecedents in the work of the American pragmatists in general, and especially John Dewey $[10,11]$. The term itself began to achieve wide usage through the work of Matthew Lipman and his Philosophy for Children movement [9]. A community of inquiry is characterized by trust and an open, critical, collaborative search for meaning and truth. In a community of inquiry all members are considered to be of equal status. All members are expected to hear one another's ideas carefully, respond to them, correct them if necessary, and develop their own ideas without fear of harsh negative criticism or humiliation from others in the community [12].

The community of inquiry is radically democratic in its ideal form. It is organized around the premise that no one individual is considered to be superior, or by virtue of role or status to have more expertise than others. As with many types of communities, it is assumed that members participate of their own free choice. In other words, participation in a true community of inquiry is voluntary. The contribution of each individual member of the community is valued, and therefore his/her background, expertise and experience is considered important to the community as a whole. We note that this radical, democratic view of collaborative learning can be found in other kinds of learning organizations that may have also been derived from Dewey, such as the Swedish "study circle” [13], and Action Learning groups [14, 15].

The success of Lipman's community of inquiry method is dependent upon the cultivation of a learning environment that is conducive to reflective, collaborative interaction. This environment supports critical, reflective, criteria-oriented, peer-correcting interaction [16]. The peer correction aspect of the community of inquiry is especially interesting. It requires an environment in which each member is carefully attentive to the opinions expressed by others. It also requires that each opinion is subjected to careful and criteria based scrutiny. This scrutiny must be expressed in constructive and caring ways. It requires that each individual take responsibility for the opinions of other members of the community, and adopt a willingness to reconsider his own judgments and opinions [16].

Some authors argue that a community of inquiry has its genesis in a joint perception of a problematic situation. According to Dewey, what makes a situation problematic is that it causes discomfort. This provides motivation which forces the group to search for ways to re-conceptualize the situation [17]. But it is important to remember that the critical thinking we hope to generate through the tool of a community of inquiry is personal. That is, it is not the community of inquiry that does the critical thinking, but rather each individual in the community. Thus it is important to remember that each student, or member, in the community must be encouraged to think for him or herself, and come to his or her own conclusions [17].

\section{B. Community of Practice}

First described by Lave and Wenger [18] a community of practice (COP) is a group of people who share a concern, a set of problems, or a passion about a topic, and who deepen their knowledge and expertise in this area by interacting on an ongoing basis.” [19]. Communities of practice have been recognized as important organizational tools for learning for number of years. They create value for organizations, 
primarily by connecting isolated and distributed pockets of expertise in knowledge [19].

According to Wenger [20 p. 45] communities of practice are very common and take a variety of forms. They may be small or big, long-lived or short-lived, co-located or distributed, homogeneous or heterogeneous, within or across organizational boundaries, spontaneous or intentional, unrecognized or institutionalized [19]. They define themselves along three dimensions: mutual engagement, a shared enterprise, and a shared repertoire of ways of doing things [20]. COPs differ from other, more formal organizational forms in several ways. Participation and membership is voluntary, and self-selected based on interest. Boundaries of the community are fuzzy. There are generally no formally defined participation requirements (job descriptions) or goals. There can be many different forms of participation and contribution.

As with communities of inquiry, at the core of communities of practice are the benefits of collaborative and collective learning present in the social interdependence theory of cooperative learning [21]. This theory suggests that cooperative learning promotes higher-level reasoning [22]. A community of experts and non-experts engages in social relations to solve problems or complete a joint endeavor by forming a social entity meeting both the technical and social needs of the community members. COPs embrace a practice-based perspective on learning called Legitimate Peripheral Participation (LPP) [18]. This perspective suggests that new or non-expert members of the community learn through interaction with and observation of expert members in the community [23]. As new and non-expert members learn the ways of the community they begin to contribute to the community until they become full participants.

According to Brown and Duguid [23], communities of practice are rich in three features: narration, collaboration, and social construction. Narrations (telling stories) "function as a usefully underconstrained means to interpret each new situation in the light of accumulated wisdom and constantly changing circumstances" [23]. The function of the community is collaborative, members of differing degrees of expertise share their information and knowledge to solve problems and create new narratives. Social construction refers to the social process of interaction to create a common understanding of the world and the emerging of members' roles within the community [23]. Communities of practice can be identified through a common language, including inside jokes, jargon and other shortcuts to communication; on-going conversations and interactions, as indicated by a lack of introductory explanations and a quick introduction of a problem to be discussed; commonly-held knowledge about members of the group, such as membership, others' expertise; and rapid sharing of knowledge and transmission of innovation [20].

By drawing on characteristics of communities of inquiry, communities of practice, and similar learning organizations such as Swedish study circles and action learning groups, we can paint an idealized picture of what a voluntary online learning community might look like in a blended, postsecondary course. It would display several characteristics:

- Voluntary participation;

- Shared interest, identity and purpose;

- Primarily student led (although instructor immediacy behaviors are critical);

- Radically democratic, even when an instructor participates;

- Engagement that values trust and open, critical, collaborative construction of meaning.

In the next two sections, we will explore several examples of such a community in action, and then several principles for its cultivation. 


\section{A VOLUNTARY ONLINE LEARNING COMMUNITY IN ACTION}

What kind of activities characterize a voluntary online learning community? In this section we have drawn several potentially illustrative examples from a graduate-level course, Introduction to Information Management, taught by the first author. The instructor encouraged, but did not require students to use the asynchronous bulletin board feature of WebCT except to publicly post assignments. In these examples, we see evidence that members of the class used the asynchronous learning technologies provided in a standard courseware package (WebCT) to voluntarily extend their collaboration beyond the three hours per week that they met together in the classroom.

This class of 60 students generated 1394 messages over the course of a semester. These messages were for the most part voluntary. Some of them involved the mandatory posting of required group assignments to bulletin boards where all members of the class could read them. Approximately half were voluntary messages posted in private forms by small groups as they collaborated asynchronously on research projects. The remainder were voluntary messages that discussed issues of interest to the class in public forums.

Figure 1 shows the distribution of postings across all class members. It is clear that the distribution of postings is unequal. Nine students generated more than 40 postings each. 17 students generated between 20 and 40 postings each. The majority of the class (34 students) generated fewer than 20 postings each.

This pattern of communication is very similar to communication patterns reported in communities of practice. Wenger at al. [19] observe and that as most communities of practice evolve, a core group of members takes on most of the leadership functions. This group is rather small, only 10 to $15 \%$ of the total number of members in the community. A second, active group is also quite small, usually another 15 to $20 \%$ of the community. The remaining members are peripheral, and participate much less frequently. In Figure 2, we present the participation structure of the asynchronous class discussions. This diagram illustrates the similarity of structure (core group, active group, peripheral group) between this class and a traditional community of practice.

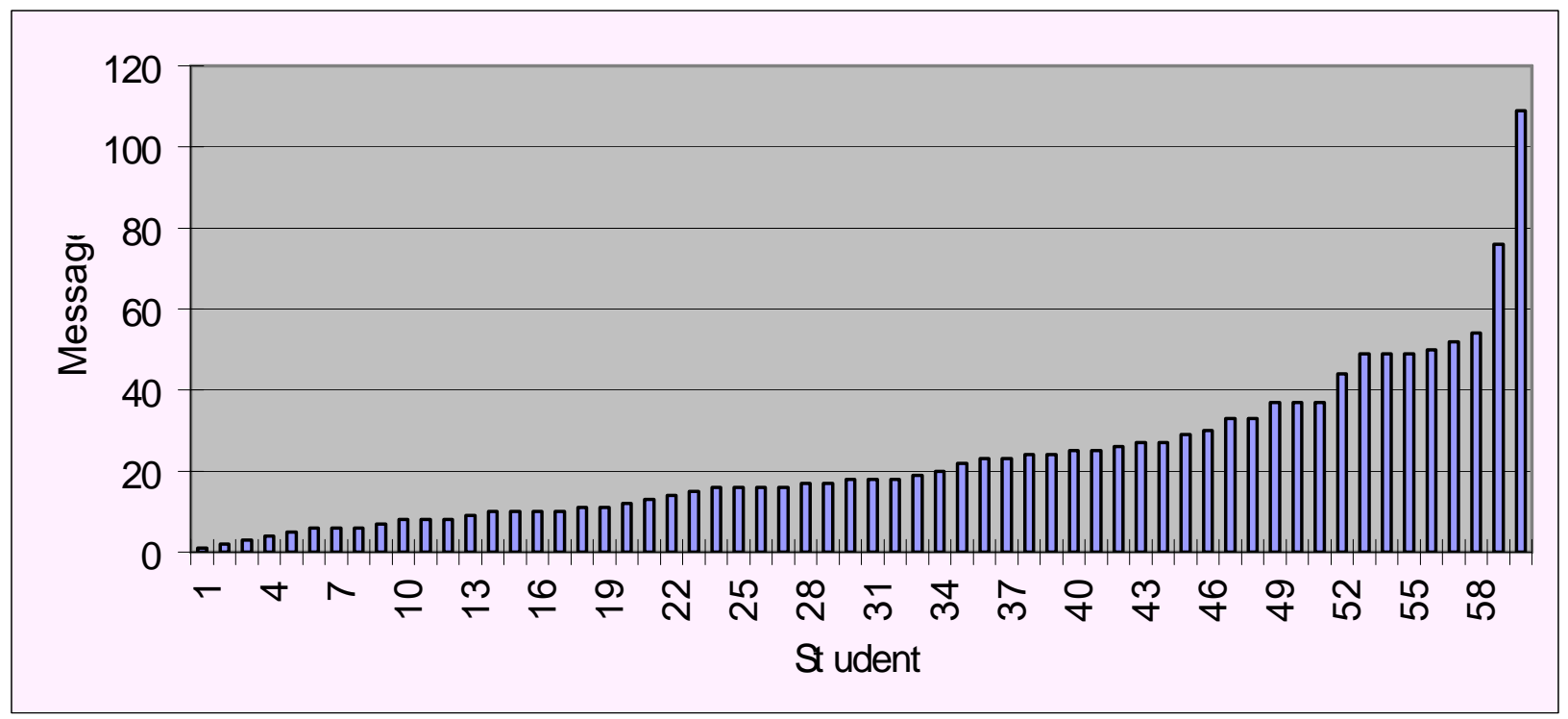

Figure 1. Distribution of Asynchronous Postings 


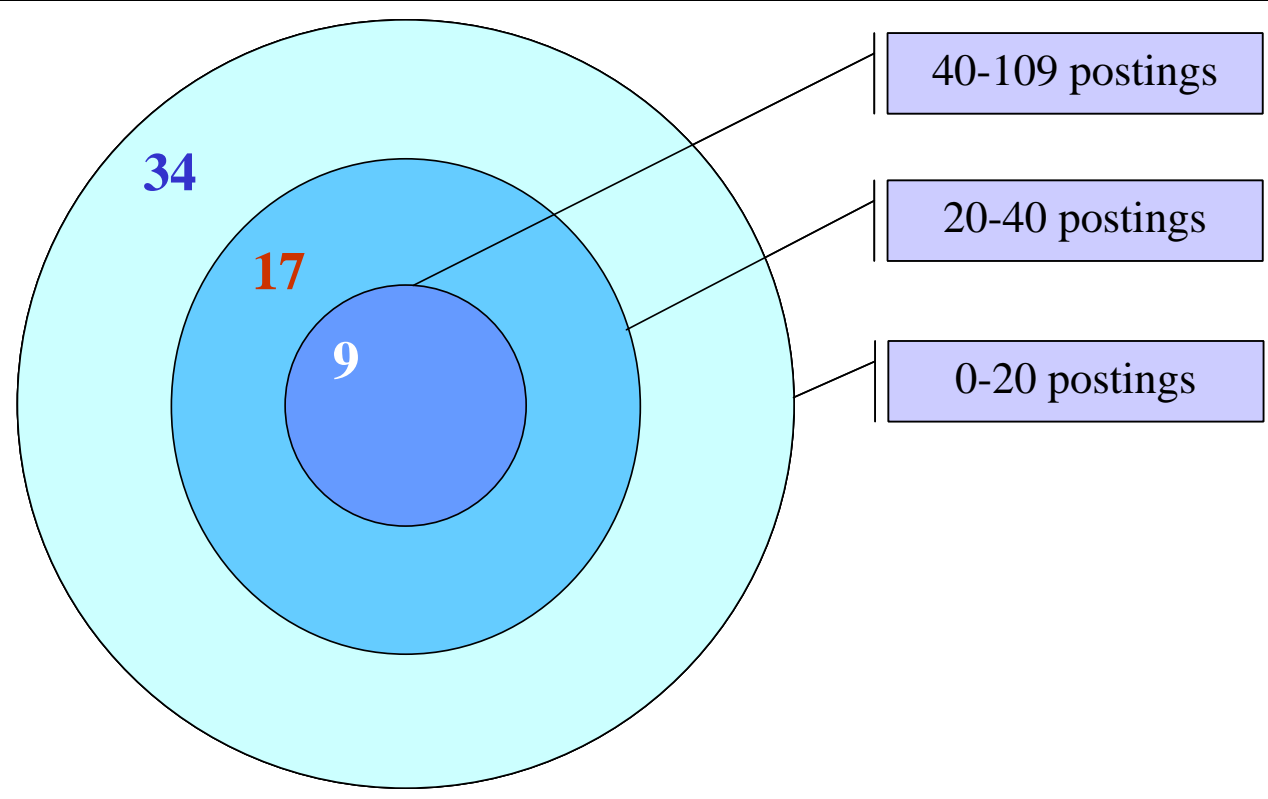

Figure 2. Participation Structure of Asynchronous Collaboration

\section{ASYNCHRONOUS ACTIVITIES THAT CHARACTERIZE A CONTINUOUS LEARNING COMMUNITY}

To better understand the purposes for which students were using the asynchronous bulletin boards, we performed an inductive content analysis of the messages posted to voluntary, public forums. We did not include the private forums in this analysis because initial inspection indicated that they were primarily used for collaboration on team research projects. In the voluntary, public forum postings, we observed five categories of asynchronous activities that supported FTF class time:

1. Challenging the instructor and/or the class

2. Continuing a FTF discussion online

3. Beginning a FTF discussion online

4. Presenting outside resources to augment class discussion

5. Asking for clarification

Table 1 shows the frequency with which each of these activities occurred over the course of the semester. The nature of these activities suggests that these voluntary, online postings have several potential benefits for both students and instructors.

Contributors benefit from reflection and sharpening their understanding by writing about their opinions and sharing them with others. Contributors may also benefit from receiving feedback. But lurkers may also benefit from being exposed to others' opinions, experiences, and understanding of the subject matter. While these are important aspects of collaborative learning, they may also be beneficial from a class administration standpoint. Instructors can rely on students to help one another with course content, which can allow the instructor to cover more advanced topics. For example, in many types of courses (e.g. sciences) instructors might spend 10 minutes of class time explaining a homework problem to one or two students in the classroom, while the rest of the class feels bored or frustrated. By encouraging the students to ask questions in online discussions before class sessions, students themselves might handle some of the 
basic questions. Further, the instructor might better assess the level of general student understanding by the questions they ask and the explanations they provide. This allows the instructor to better prepare for class.

\begin{tabular}{|l|l|}
\hline Activity & Occurrences \\
\hline Challenging the instructor and/or the class & 20 \\
\hline Continuing a FTF discussion online & 35 \\
\hline Beginning a FTF discussion online & 11 \\
\hline Presenting outside resources to augment class discussions & 54 \\
\hline Asking for clarification & 6 \\
\hline
\end{tabular}

Table 1. Asynchronous Activities Supporting FTF Class

In the remainder of this section, we present an example of each category.

\title{
A. Example 1: Challenging the Instructor and/or the Class
}

\author{
(25 postings over 8 days)
}

\section{The Grenade}

In this example, a student good-naturedly expressed his disapproval of a strategic planning methodology (Scenario Planning), which had been presented by the instructor and discussed in the FTF class. This challenge, which generated 25 postings over eight days, resulted in a deeper discussion of the conceptual underpinnings of this method.

Student 1: As an arrant knave I would like to lob a grenade into this tranquil space and see its after effect. I beg to differ with $B$. [the instructor] and the rest of the class on "Scenario Analysis." I believe it is preposterous to do an analysis on a Scenario. An analysis is to be performed on an objective entity either in its past, present or future form. These few sentences will help me to drive my point!

Student 2:-Student 1, I'll take your grenade and lob it back in your general direction... It is perfectly legitimate to analyze a work of fiction. It is understood that the actual future will not replicate exactly any one particular scenario. However, the process of analyzing can provide insight in terms of approaching and preparing for a given future.

Student 3: Scenarios, as defined, developed and used in business do not fit with the m$W$ definition you've quoted. Societal changes and common use eventually cause additional definitions to be added to word meanings...

What are scenarios? For a start they are not projections, predictions or preferences. Rather they are coherent and credible alternative stories about the future, incorporating a spectrum of ideas and focusing on issues that are important for our business decisions today." (Davis, Ged (2002) Questioning assumptions: exploring alternative business futures. Swedbank Conference, Stockholm, Accessed October 21, 2003, Available from http://www.shell.com/static/media-en/downloads/questioning_assumptions.pdf, Internet) 
Student 4: Student 1, Come on now. You lobbed the grenade and had several lobbed back at you. You must either provide information that will lend credibility to your argument or admit that your original presumptions about the value of scenario planning were wrong.

Note my terminology - "scenario planning." I think you are missing an important point that was mentioned earlier in this thread. Our task was to analyze the implications of the scenario and not the scenario itself...

Student 1 (the original challenger, withdrawing from the field):

"What we cannot speak about we must pass over in silence" the last statement in the book "Tracatatus Logico -Philosophicus" By Wittgenstein

\section{B. Example 2: Continuing a FTF Discussion Online}

(25 postings over 22 Days)

\section{The Inverted Pyramid}

In this example, a discussion that had begun in the last few minutes of a FTF class session was continued online. In the classroom, a student ("Student 2") had challenged the instructor's ideas about the relative importance of technical, conceptual, social, and leadership skills. The instructor's presentation used a pyramid as a graphic device. Student 2 had argued that the instructor's pyramid should be inverted, turned on its head. Because the class period ended with the dispute unresolved, the argument spilled over into the asynchronous bulletin board, generating 25 postings over the next 22 days. What had been a predominantly dyadic FTF discussion in class evolved into a much more participatory online discussion, with students presenting different points of view while the instructor remained silent.

\section{Student 1}

I must say that Student 2's comment on inverting the pyramid was very creative and stuck in my head, even though I don't share his same vision. For me a strong understanding of the technical side is very important. It enables the person to understand exactly how the product, that he is in charge of either developing or implementing, really works. I consider this to be the foundation of the whole field.

\section{Student 2}

I seem to be rallying support... The link below is a great read!!!

"Half Empty Surveys conclude that half of all IT vacancies go unfilled, and that half of all development staff are working on projects that will eventually fail. This suggests a shortage of management skills rather than the much-vaunted shortage of technical skills. But managers seldom recognize a skill deficit in themselves, so they 'find' the problem elsewhere and report accordingly. Proper training of project managers would have a far more sustainable benefit than scouring the far-flung empire for the hot skills of the moment." - Stephen Cumbers, report to British Parliament.

http://www.topquark.co.uk/articles/skills_crisis.html 


\title{
C. Example 3: Beginning a FTF Discussion Online
}

(3 postings over 2 days)

\section{Game Theory}

In this example, a student followed up on a classroom lecture devoted to "Developing Strategy" with a posting that pointed the class to a web site about game theory, a topic which had not been discussed in the lecture. In addition to providing access to an excellent resource (a web site has been a staple in subsequent sections of the class), the posting generated additional FTF discussion about game theory in the next FTF class session.

\begin{abstract}
Student 1:
I find that Game Theory is a wonderful mathematical tool for developing Strategies. The chapters contained in this URL. http://william-king.www.drexel.edu/top/eco/game Igame.html is worth reading. This theory, which starts with a narration of "Prisoners Dilemma," progresses towards a win-win Cooperative game strategy of Information Technology Companies and arrives at the fundamentals of neoclassical economy theory of strategies as Nash Equilibrium, named after John Nash.

\section{Student 2:}

I have a question on the Prisoner's Dilemma theory: if both parties are only interested in saving themselves, and thus both choose to confess, they are obviously making it worse for themselves (10 years each in prison). However, in the business world, how is it possible for companies to work together yet still remain competitive?

\section{Student 1:}

The problem is, the burglars are incommunicado. Had they had the pleasure of communicating, seldom allowed in a criminal investigation, then it is a Cooperative game. Then what you say would be correct; they would have got away with 1 year of prison time each. I suggest you read this scenario "Choosing Information Technology" in the same URL, where two Technology companies develop their strategies and they are better off if they cooperate.
\end{abstract}

\section{Example 4: Presenting Outside Resources to Augment Class Discussions \\ (5 postings in 16 days)}

\section{IT Doesn't Matter}

The most common example of pro-community behavior was sharing information about links to useful Internet resources. Once this process began, it gathered momentum, as students imitated the prosocial behavior of their colleagues.

Student 1: While surfing the CNET website, I found a very interesting debate video on, who else, but Nicholas Carr (author of IT Doesn't Matter) and CEO of Sun Microsystems. Go to http://news.com.com/ and watch for yourself. It's the first one on the right hand side. Discussion is similar to the one we had in class a few weeks ago. 
Student 2: Thanks so much for posting the information on the video, it was very interesting and extended our class discussion a bit. It was good to see Carr and Sun's CEO debate a bit.

Student 3: I agree with the others, I'm very glad you posted this site. I thought the particular discussion that you alluded to was interesting, but much of the other information on the website is pertinent for the class as well.

\section{E. Example 5: Asking for Clarification}

(13 posting over 10 Days)

\section{Military Intelligence}

In most examples of asking for clarification, a student who is confused about some aspect of the material presented in class asks for further information. Occasionally however the issue requiring clarification can be more emotionally charged. Here, a student didn't fully understand (and was somewhat offended by) an instructor classroom comment to another student that, "Your statement, like military intelligence, is an oxymoron.” The student misinterpreted the comment as an insult to the American military, then engaged in both Afghanistan and Iraq. She was understandably reluctant to question the instructor in class, but it bothered her enough that she raised the issue later that evening in the bulletin board. This led to a discussion over the next 10 days that (hopefully) got the instructor off the hook for a careless comment, and even managed to introduce a short discussion of literature.

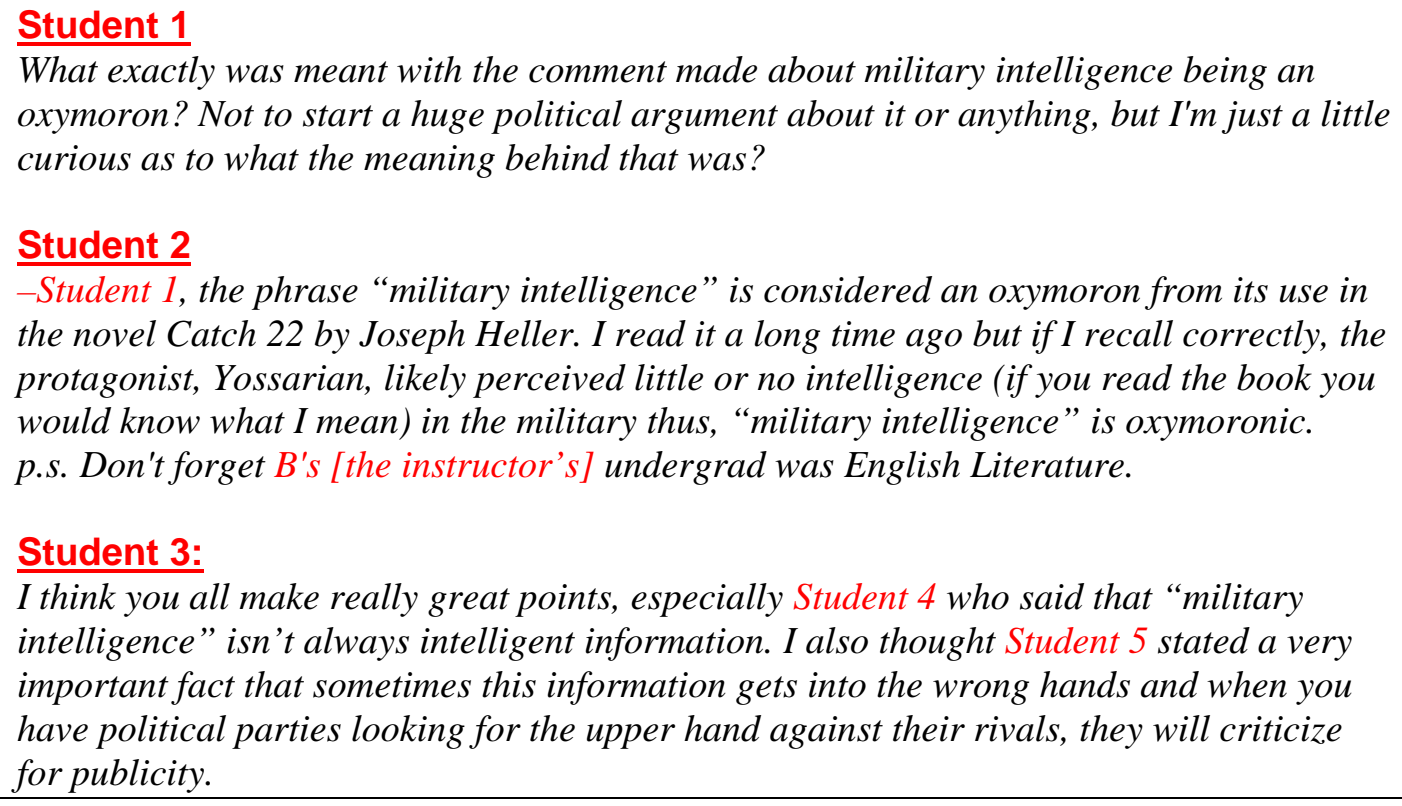

\section{Student 2}

-Student 1, the phrase "military intelligence" is considered an oxymoron from its use in the novel Catch 22 by Joseph Heller. I read it a long time ago but if I recall correctly, the protagonist, Yossarian, likely perceived little or no intelligence (if you read the book you would know what I mean) in the military thus, "military intelligence" is oxymoronic. p.s. Don't forget B's [the instructor's] undergrad was English Literature.

\section{Student 3:}

I think you all make really great points, especially Student 4 who said that "military intelligence" isn't always intelligent information. I also thought Student 5 stated a very important fact that sometimes this information gets into the wrong hands and when you have political parties looking for the upper hand against their rivals, they will criticize for publicity. 


\title{
V. CONTINUOUS ONLINE LEARNING COMMUNITIES: PRINCIPLES OF CULTIVATION
}

\begin{abstract}
Because communities of practice are voluntary, what makes them successful over time is their ability to generate enough excitement, relevance, and value to attract and engage members. Although many factors such as management support or an urgent problem can inspire a community, nothing can substitute for this sense of aliveness. ”[19 p. 50]
\end{abstract}

What is true for communities of practice is also true for communities of inquiry, and thus can be applied to continuous online learning communities in blended environments. Such communities cannot be created and managed by fiat. Because they are voluntary, they must be cultivated. The garden metaphor, suggested by Wenger, et al., is appropriate. Because the community is an organic, living form, it cannot be manufactured, legislated, or commanded to grow. However the conditions optimal for growth can be provided. Just as the soil can be prepared, and fertilizer and water supplied, conditions conducive for the growth of a continuous learning community can be created. We offer the following 10 principles not as an exhaustive checklist, but simply as a starting point for instructors who wish to begin the process. (Several of these principles $(1,2,3,4,5)$ are adapted from Wenger, McDermott, and Snyder's [19] guidelines for cultivating communities of practice.)

1. Focus on value and expect different levels of participation. In communities of practice value usually comes from a focus on the most pressing and urgent current problems. It has also been found in communities of practice that is very difficult to determine expected value in advance. Wenger, et al. [19] suggest that a more fruitful approach is to create activities and events that will allow potential value to emerge. Because people have different levels of interest and value different things, it is unrealistic to expect that all members will participate equally. (Remember that in most communities of practice a core group of members takes on most of the leadership functions. A second, active group is also quite small, and the remaining members are peripheral, and participate much less frequently. See figure 2 above.) Most experienced instructors will recognize that this pattern holds as well in FTF and online classes. While it may be appropriate to reward those who contribute more, we should not lose sight of the fact that "lurkers" may also receive significant benefit from the community.

2. Focus on the design of community spaces. Develop both public and private community spaces. For example, some bulletin boards will be "public," open to all members of the class. Others, however, will be "private," creating spaces where small groups can collaborate. Create both familiar and novel spaces. Familiar structures or spaces become comfortable, allowing people to be relaxed and natural and their interactions. Like a neighborhood bar or cafe, the community becomes a "place" where people can ask questions and share advice in a relaxed manner. But novelty is also important, generating a stimulus for new ideas and creative thinking. For example, in addition to forums for discussion of course topics, we created a forum where students contributed and discussed candidate final exam questions. This unusual forum startled students into thinking creatively about what the important lessons from the course should be.

3. Welcome the unexpected. Give up control. Allow the community to evolve and self-organize according to principles that you may not be able to anticipate. Be flexible. Recognize and welcome the fact that you cannot predetermine where discussions will go. As new students enter the community every semester, their specific interests will focus the attention of the community in new directions. This dynamic process cannot be prevented, and should be nurtured. 
4. Welcome outside perspectives. Just as visitors enhance the traditional classroom, outsiders also provide a useful presence in the virtual community. It is especially useful to invite those who were guest speakers in the FTF classroom to join discussions in the online bulletin boards. Good community design brings not only information, but also people from outside the community.

5. Create a rhythm for the community. The tempo of interaction in a community has an important effect on how community "feels." The rhythm should be strong and steady, not too fast, not too slow. The rhythm of the community is created by the sequence and timing of regular events. The weekly FTF class meeting provides a regular rhythmic punctuation. Regularly scheduled, voluntary discussion sessions conducted by graduate assistants contribute similarly to the community's tempo. The timing of major assignments and exams are also important rhythmic markers. Professors (or graduate assistants) who post comments and questions at the same time every week create one kind of rhythm. Those who post immediate responses create a very different rhythm. In one class, a professor batched his comments while his GA posted immediate responses, creating a kind of counterpoint.

6. Make expectations clear. Professors should assume that students will at first be unfamiliar with the concept of a voluntary, continuous learning community. The idea and its associated expectations should be clearly and repeatedly described. This process begins with syllabus language, and continues with repeated FTF and online reminders. An example of syllabus language is included below. It not only defines a continuous learning community, but also provides concrete examples of expected community behaviors. In addition, teachers can make effective use of narrative to provide vivid illustrations of past pro-community behavior. Stories can be excellent vehicles to communicate desired community values.

\section{Sample Syllabus Language}

An important dimension of our continuous learning community will be the asynchronous discussions that occur in WebCT bulletin boards. These discussions may continue topics begun in the FTF classroom, or may anticipate them. In some cases, students have conducted discussions entirely asynchronously, without ever having them emerge in the FTF class.

I will make a qualitative assessment of your contribution to class discussions. Your contribution score will not be based on the number of postings or the number of words you write but rather on your ability to make interesting points that stimulate discussion and interest from others over the course of a semester. The most valuable commentaries tend to be well supported and thought-out rather than simply provocative. Here are some things that I look for in evaluating the quality of your posts:

- Asking pointed questions about readings

- Asking questions about postings made by other students

- Answering the questions of other students

- Engaging fellow students in dialogue

- Contributing information (e.g. links to articles) to the community. 
7. Model community behavior. It is important that teachers not only "talk the talk" but also "walk the walk". Students will imitate observed behavior. It is also useful in this regard to have one or more graduate assistants assist in modeling desired behavior. Do the things that you want your students to do:

- Challenge assumptions.

- Ask questions.

- Continue discussions from the FTF class.

- Challenge an in-class comment on line

- Bring in serendipitous readings

8. Reinforce desired behavior. Students will respond positively when community behavior is publicly recognized and praised. When it becomes clear that you are paying attention, students will respond. Some ways to provide positive reinforcement:

- Thank students online for valuable contributions

- Review the week's postings at the beginning of each FTF class

- Recognize contributors by name in each FTF class

- Follow online leads in FTF class

9. Integrate online and FTF components. It will be helpful to reserve an unstructured period at the beginning of each FTF class to review, comment on, and continue interesting discussions begun in the online forums. It may be difficult for some instructors to give up valuable class time when there seems to be so much material to cover. Nevertheless, the benefits of this practice are significant. In addition to the student reinforcement effect described above, this practice emphasizes a sense of continuity that helps students recognize the value of the online discussion. In addition, instructors will be surprised by the unexpected and interesting additions to their classes.

10. Publish all student assignments. Many students have formed the expectation that their assignments are private, dyadic communications between them and their instructors. This has at least two undesirable consequences. First, if a student is tempted to slack off on an assignment, there is no pressure of community peer embarrassment to motivate other behavior. More importantly, dyadic assignments that are never seen by anyone other than the instructor are lost forever, and have no opportunity to be shared. As a result, a significant proportion of the knowledge work performed in our institutions of higher learning is never shared, and has no opportunity to influence the social fabric. Publishing all student assignments creates cultural norms that motivate higher-quality work, and encourage the sharing of knowledge.

11. Get out of the way. Let the students do the heavy lifting. A successful community evolves only to the extent that most of the work is done by its members.

\section{CONCLUSION}

In this paper we have talked about using asynchronous technology to create a continuous learning community in FTF courses. We have discussed the theoretical concepts and values that are the foundation of such a community, described some of the activities that take place there, and presented principles of cultivation that we believe will help instructors nurture such communities in their own classes. The student behaviors we have observed in our own classes have convinced us that the emergence of a voluntary online learning community is possible in any course. Nevertheless, there are challenges that must be overcome if this practice is to become widespread. 
Although most US university students in this age belong to a number of communities (e.g. interest groups, extra curricular activities, networks of friends) and use multiple forms of communication technologies (e.g. email, instant messenger, bulletin boards) on a daily basis to stay connected to these communities, they are not necessarily used to viewing or treating their college courses in that way. Teachers may not necessarily be ready or equipped to view their courses as a continuous obligation with various online interaction dimensions beyond those of the classroom. In addition, many instructors do not believe that students will voluntarily do more than they are explicitly required to do. This suggests that there must be a cultural change in the way both student and instructors view their courses. Both have to see and believe in the value provided by blended learning communities. This change can start with instructors and students who have had positive outcomes. More importantly, such change must be facilitated and supported by administrators as well. Providing the right tools (e.g. communication technologies), training to use the tools, and a willingness to experiment are critical ingredients. The availability and championship of voluntary, blended learning communities at the department or university level will begin the process of changing student and teacher expectations.

While the ideas presented in this paper are grounded in well accepted learning theory and the observation of actual classroom communities, we recognize that anecdotal observations cannot substitute for more rigorous research. In the remainder of this section we offer suggestions for a future research agenda in this domain. We propose that research on continuous learning communities should investigate three broad questions. Figure 3 shows the relationship between the constructs represented in these questions.

\section{A. What Are the Characteristics of a Thriving Online Learning Community?}

In other words, how do we recognize such a community when we see one? In this paper we have described several activities that may be important characteristics of a voluntary online learning community. These included challenging the instructor and/or the class, continuing a FTF discussion online, beginning a FTF discussion online, presenting outside resources to augment class discussion, and asking for clarification. All of these are examples of interaction, an essential ingredient that has been identified by several researchers $[24,25]$ as being at the heart of online learning communities. We believe that a thorough exploration of the nature of interactions present in a voluntary online learning community will be useful approach to better understanding this phenomenon.

\section{B. What Behaviors (On the Part of Teachers and Students Alike) Create, Sustain, and Modify the Structures of a Voluntary Online Learning Community?}

We have identified several behaviors and attitudes on the part of teachers that we believe contribute to the cultivation of a continuous learning community. Research should systematically investigate which of these (or others) are most important.

\section{What Learning Outcomes Can Reliably be Expected to Occur as a Result of the Existence of a Continuous Community of Inquiry?}

Implicit in our argument thus far is the assumption that continuous learning communities are good. We believe this to be true, but the validity of this assertion should be rigorously tested. We must not only investigate whether or not improved learning outcomes can be attributed to continuous learning communities, we must also strive to better understand the processes by which such effects are achieved. 


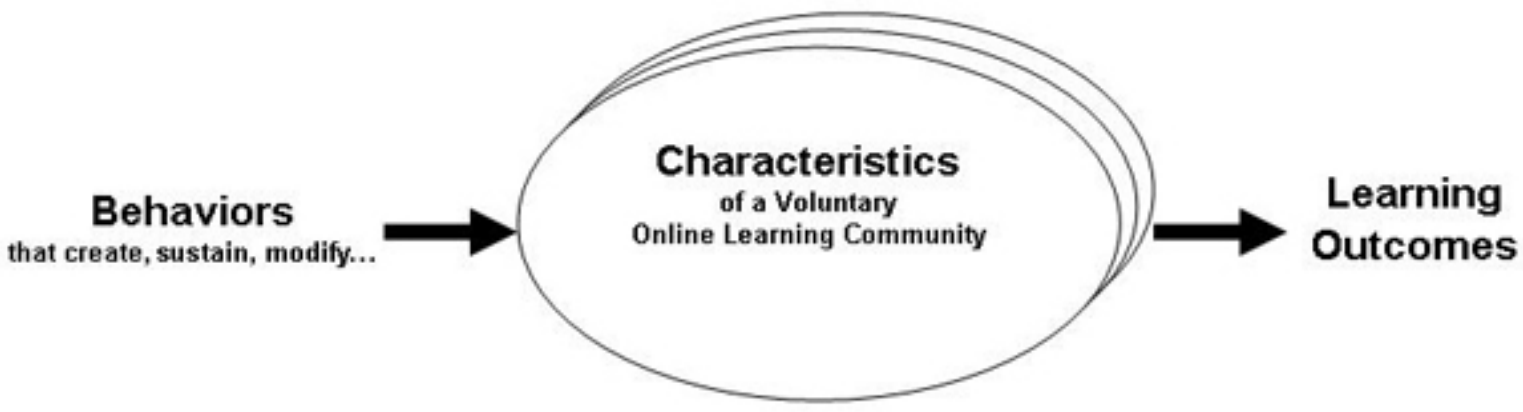

Figure 3. Research Model for Voluntary Online Learning Communities

Garrison and Kanuka [6] have argued that blended learning has the potential to transform educational practice. But they note that if this is to occur, we must recognize that blended learning requires the skillful integration of FTF and online activities, not simply layering one upon the other. They point out that while blended learning has enormous versatility and potential, it creates many daunting challenges on the front end of the design process. It is our belief that thinking about design in terms of cultivating a continuous learning community can be a useful approach to that process.

\section{REFERENCES}

1. Driscoll, M. Blended learning: Let's get beyond the hype. E-learning, 2002.

2. Harasim, L. Online education: Perspectives on a new medium. New York: Prager/Greenwood, 1990.

3. Benbunan-Fich, R. and S. R. Hiltz. Impacts of Asynchronous Learning Networks on Individual and Group Problem Solving: A Field Experiment. Group Decision and Negotiation 8: 409-426, 1999.

4. Heckman, R. and H. Annabi. A Content Analytic Comparison of Learning Processes in Online and Face-to-Face Case Study Discussions. Journal of Computer-Mediated Communication [Online], 2005.

5. Anderson, T. and H. Kanuka. Online Forums [1]: New Platforms for Professional Development and Group Collaboration. Journal of Computer Mediated Communication, 3: 1997.

6. Garrison, D. R. and H. Kanuka. Blended learning: Uncovering its transformative potential in higher education. Internet and Higher Education 7: 95-105, 2004.

7. Kvavik, R.I.a.e. Convenience, communications, and control: how students use technology. In D. Oblingr and J. Oblinger, (Eds.), Educating the Net Generation, Educause, 2005.

8. Garrison, R., T. Anderson, and W. Archer., Critical thinking in a text-based environment: Computer conferencing in higher education. The Internet and Higher Education 2: 87-105, 2000.

9. Lipman, M. Philosophy for Children. Metaphilosophy 7: 17-39, 1976.

10. Daniel, M. John Dewey and Matthew Lipman: Pragmatism in Education.” In D. Camhy, (Ed.), In Children: Thinking and Philosophy, Sankt Augustin: Academia Verlag, 1994.

11. Ohlsson, R. An early form of the community of inquiry: The study circle. Thinking 14: 27-28, 1998.

12. Sharp, A. What is a community of inquiry? Journal of Moral Education 16: 37-44, 1987.

13. Olson, D. R. The world on paper: The conceptual and cognitive implications of reading and writing. Cambridge and New York: Cambridge University Press, 1994.

14. Spence, J. Action learning for individual and organizational development. ERIC Clearinghouse for Adult, Career, and Vocational Education. Columbus, OH, 1998.

15. Revans, R. W. The ABC of action learning. Bromley: Chartwell-Bratt, 1983.

16. Hagaman, S. The community of inquiry: an approach to collaborative learning. Journal of Issues and Research 31: 149-157, 1990. 
17. Scormicov, S. The Problematic Community of Inquiry: The Socrates and Kant of Lipman and Dewey. Thinking: The Journal of Philosophy for Children 15: 41-45, 2000.

18. Lave, J. and E. Wenger. Situated learning: Legitimate peripheral participation. Cambridge: Cambridge University Press, 1991.

19. Wenger, E., R. McDermott and W. Snyder. Cultivating Communities of Practice. Cambridge, MA: Harvard Business School Press, 2002.

20. Wenger, E. Communities of Practice: Learning, Meaning, and Identity. New York: Cambridge University Press, 1998.

21. Johnson, D. and R. T. Johnson. Effects of Cooperative and Individualistic Learning Experience on Interethnic Interaction. Journal of Educational Psychology 73: 444-449, 1981.

22. Aviv, R. Educational performance of ALN via content analysis. The Journal Of Asynchronous Learning Networks 4: 2000.

23. Brown, J. S. and P. Duguid. Organizational Learning and Communities-of-Practice: Toward a Unified View of Working, Learning, and Innovation. Organization Science 2: 40-57, 1991.

24. Swan, K. Building Learning Communities in Online Courses: the importance of interaction., Education, Communication \& Information 2: 23-49, 2002.

25. Moore, M. G. Three types of interaction. American Journal of Distance Education 3: 1-6, 1989.

\section{ABOUT THE AUTHORS}

Dr. Robert Heckman is Associate Professor and Director of the Graduate Program in Information Management at the School of Information Studies, Syracuse University. He teaches courses in strategic management of information resources. His current research is focused on information management issues including effective use of asynchronous learning networks, leadership in virtual teams, and discretionary technology-mediated collaboration. He received his Ph.D. in Information Systems from the University of Pittsburgh in 1993.

Hala Annabi is an assistant professor at the Information School at the University of Washington. Hala Annabi's research addresses the effects of information technology on learning in both the work and educational settings. More specifically she studies how the new forms of computer mediated work affect individual and group learning in distributed work groups. Additionally, she is interested in the affects of asynchronous learning networks on learning and community building in educational settings. Her teaching interests are in the impact of information technology in organizations, social informatics, knowledge management, and organizational behavior. Hala holds a Ph.D. in Information Science and Technology from Syracuse University and an M.B.A. and B.S. from Le Moyne College. 